\title{
PENGUJIAN USABILITY GOOGLE CLASSROOM BERDASARKAN MODEL USE-QUESTIONNAIRE
}

\author{
Suci Ramadhani Arifin*1, Etha Gustin Merdekawati \\ ${ }^{1}$ Sekolah Tinggi Manajemen Informatika dan Komputer Dipanegara, Makassar \\ ${ }^{2}$ Politeknik Informatika Nasional, Makassar \\ Email: 1'suci.arifin@dipanegara.ac.id, ${ }^{2}$ ethagustinmw@gmail.com \\ *Penulis Korespondensi
}

(Naskah masuk: 02 Juli 2020, diterima untuk diterbitkan: 17 November 2021)

\begin{abstract}
Abstrak
Pembelajaran online adalah solusi ketika lembaga pendidikan ditutup karena wabah COVID-19. Sistem Manajemen Pembelajaran (LMS) merupakan alat untuk memfasilitasi pembelajaran online. Google Classroom dianggap sebagai salah satu LMS yang paling cepat diimplementasikan di pendidikan tinggi. Tujuan dari penelitian ini adalah untuk mengukur tingkat usability Google Classroom sebagai salah satu alat yang digunakan untuk memfasilitasi pembelajaran online di STMIK Dipanegara Makassar. Tingkat usability akan menentukan apakah penggunaan layanan Google Classroom telah efektif, efisien, dan memberikan kepuasan terhadap mahasiswa. Tingkat usability Google Classroom diukur menggunakan USE-Questionnaire. Berdasarkan hasil pengukuran usability terhadap Google Classroom diperoleh nilai rata-rata untuk keseluruhan variabel Usefulness (Daya Guna), Ease of Use (Kemudahan Penggunaan), Ease of Learning (Kemudahan Belajar), dan Satisfaction (Kepuasan Pengguna) adalah 459,1 atau sebesar 76\%. Maka dapat disimpulkan bahwa mahasiswa setuju tingkat usability Google Classroom dirasakan sudah baik dan penggunaan layanan Google Classroom telah efektif, efisien, dan memberikan kepuasan terhadap mahasiswa dengan tingkat presentase sebesar $76 \%$.
\end{abstract}

Kata kunci: Pengujian Usability, Google Classroom, Pembelajaran Online.

\section{USABILITY TESTING OF GOOGLE CLASSROOM BASED ON USE-QUESTIONNAIRE MODEL}

\begin{abstract}
Online learning is a solution when educational institutions are closed because of the COVID-19 outbreak. Learning Management System (LMS) is a tool to facilitate online learning. Google Classroom is considered as one of the fastest implementing LMSs in higher education. The purpose of this research is to measure the usability level of Google Classroom as one of the tools used to facilitate online learning at STMIK Dipanegara Makassar. The level of usability will determine whether the use of Google Classroom services has been effective, efficient, and gives satisfaction to students. Google Classroom usability level is measured using USE-Questionnaire. Based on the results of usability measurements on Google Classroom, the average value for all variables of Usefulness, Ease of Use, Ease of Learning, and Satisfaction is 459.1 or $76 \%$. So it can be concluded that students agree that the usability level of Google Classroom is good and the use of Google Classroom services has been effective, efficient, and provides satisfaction to students with a percentage level of $76 \%$.
\end{abstract}

Keywords: Usability Testing, Google Classroom, Online Learning.

\section{PENDAHULUAN}

Sejak awal Maret 2020, STMIK Dipanegara Makassar telah mengalami migrasi masif yang belum pernah terjadi sebelumnya dari pembelajaran tatap muka ke pembelajaran online. Hal tersebut merupakan dampak dari pandemi COVID-19 yang menyebabkan pemerintah pusat hingga daerah mengambil kebijakan untuk meliburkan seluruh lembaga pendidikan sebagai langkah pencegahan meluasnya penularan virus corona (Abidah et al., 2020).

Pembelajaran online adalah solusi ketika lembaga pendidikan ditutup karena wabah COVID19 (Verawardina et al., 2020). Unesco (Unesco, 2020) juga mendukung pembelajaran dilakukan secara online dan menyatakan bahwa para mahasiswa harus terus mendapatkan hak-hak mereka dengan terus melanjutkan pendidikan, meskipun dilakukan dari 
jarak jauh sehingga pembelajaran online diperlukan agar kegiatan belajar mengajar terus berjalan.

Sistem Manajemen Pembelajaran (Learning Management System/LMS) merupakan alat untuk memfasilitasi pembelajaran online. Beberapa LMS yang diketahui telah digunakan secara global selama beberapa dekade seperti Moodle, Blackboard, Canvas, dan Google Classroom (Kaewsaiha, 2019). diantara aplikasi tersebut, Google Classroom dianggap sebagai salah satu alat yang paling cepat diimplementasikan di pendidikan tinggi (Alqahtani, 2019).

Google Classroom adalah perangkat lunak yang diperkenalkan sebagai fitur dari Google Apps for Education yang dirilis Agustus 2014. Penggunaan Google Classroom akan membuat proses pembelajaran di tingkat perguruan tinggi lebih efektif karena dosen sebagai pendidik dan mahasiswa dapat berkomunikasi kapan saja melalui Google Classroom (Septiyana and Widiyaningsih, 2020).

Pemanfaatan Google Classroom dapat diakses multiplatform yaitu melalui komputer dan smartphone. Dosen dan mahasiswa dapat mengunjungi situs https://classroom.google.com atau dapat mengunduh aplikasi Google Classroom secara gratis melalui PlayStore di Android atau melalui App Store di iOS (Henukh et al., 2020).

Efektivitas sistem informasi tergantung pada kualitasnya yang ditentukan oleh karakteristik seperti fungsionalitas, keandalan, usability, dan portabilitas (Bevan and Earthy, 2017; Jamil et al., 2020). Usability merupakan salah satu paramater penting pada pengukuran kualitas sistem informasi atau perangkat lunak (Prastyo et al., 2019). Usability didefinisikan sebagai kemudahan penggunaan dan sejauh mana produk yang digunakan oleh pengguna memenuhi efektivitas, efisiensi, kepuasan dan tujuan tertentu (Rangraz Jeddi et al., 2020). Usability yang buruk akan mengurangi penggunaan sistem informasi dan menghambat penerimaan sistem informasi oleh pengguna yang akan berdampak negatif pada efektivitas dan efisiensi sistem informasi serta akan mengurangi kepuasan pengguna (Blanchard et al., 2018; Diemert et al., 2017). Oleh karena itu, sangat penting untuk mengetahui tingkat usability suatu sistem.

Untuk mengukur usability, ada beberapa model yang dapat digunakan, diantaranya adalah model USE-Questionnaire. Model USE-Questionnaire merupakan model usability yang cukup komprehensif, karena tiga (3) aspek utama usability yaitu efektivitas, efisiensi, kepuasan pengguna, telah terakomodasi di setiap komponen dari setiap item pertanyaan kuisioner (Rizal et al., 2020).

Dalam penelitian ini, model USE-Questionnaire diadopsi dengan tujuan untuk mengukur tingkat usability Google Classroom sebagai salah satu alat yang digunakan untuk memfasilitasi pembelajaran online di STMIK Dipanegara Makassar. Google Classroom dimanfaatkan sebagai media untuk memberikan pengumuman terkait mata kuliah, membagikan materi perkuliahan dan materi pendukung lainnya, mendistribusikan tugas kepada mahasiswa, pengumpulan tugas, memberikan penilaian kepada tugas-tugas yang dikumpulkan mahasiswa dan tugas yang telah selesai diberikan nilai akan dikirim kembali kepada mahasiswa agar mahasiswa mengetahui jumlah skor yang didapatkan. Selain itu, Google Classroom juga digunakan sebagai media diskusi antara dosen dengan mahasiswa dan antar sesama mahasiswa. Untuk menunjang proses pembelajaran, penggunaan Google Classroom dipadukan dengan Google Meet untuk membawakan materi melalui video konferensi dan grup WhatsApp untuk media komunikasi selain fitur forum diskusi Google Classroom.

Tingkat usability Google Classroom diukur menggunakan USE-Questionnaire (Usefulness, Satisfaction, dan Ease of Use) yang dikembangkan pada tahun 2001 sebagai alat ukur subjektif usability suatu produk atau layanan yang terdiri atas 30-item pertanyaan yang terbagi kedalam empat dimensi usability: Usefulness, Ease of Use, Ease of Learning, dan Satisfaction (Gao et al., 2018).

Pengujian usability yang dilakukan pada penelitian ini diharapkan dapat memberikan gambaran mengenai tingkat usability Google Classroom yang akan menentukan apakah penggunaan layanan Google Classroom telah efektif, efisien, dan memberikan kepuasan terhadap mahasiswa.

Penelitian sebelumnya terkait pengukuran usability sistem dengan USE-Questionnaire telah dilakukan oleh Rizal (Rizal et al., 2020) yang melakukan pengujian usability berbasis USEQuestionnaire terhadap aplikasi Mozita, fokus kepada bagian antarmuka pengguna aplikasi. Hasil pengujian usability menunjukkan bahwa aplikasi Mozita memiliki nilai usability yang tinggi sehingga dapat disimpulkan bahwa aplikasi Mozita telah memenuhi kebutuhan pengguna untuk membantu dalam menyelesaikan pekerjaannya.

Penelitian selanjutnya dilakukan oleh Hariyanto et al (Hariyanto et al., 2020) dengan tujuan melaksanakan evaluasi usability terhadap sistem elearning adaptif yang telah dikembangkan berdasarkan gaya pembelajaran mahasiswa dan tingkat pengetahuan awal menggunakan USEQuestionnaire. Temuan penelitian Hariyanto [16] menunjukkan usability dari sistem e-learning adaptif untuk mahasiswa diterima dengan baik di semua aspek usability.

Selanjutnya, Lubis et al (Lubis et al., 2020) melakukan evaluasi usability sistem aplikasi mobile JKN (Aplikasi Kesehatan BPJS) menggunakan USEQuestionnaire yang bertujuan untuk mengetahui seberapa unggul sistem tersebut. Hasil penelitian dapat mendukung pengembangan dan kemajuan aplikasi ini dan kelemahan sistem yang dapat menjadi 
masukan bagi pengembang aplikasi agar ditingkatkan ke arah yang lebih baik.

Jubaedah et al (Jubaedah et al., 2020) melakukan pengujian usability pada rubrik penilaian kinerja elektronik yang bertujuan untuk mengetahui apakah aplikasi tersebut sudah sesuai dengan kebutuhan pengguna atau tidak menggunakan menggunakan lembar evaluasi USE-Questionnaire. Hasil penelitian memberikan beberapa masukan penting sebagai panduan untuk perbaikan aplikasi.

Darmawan et al (Darmawan et al., 2020) menganalisis usability aplikasi sistem pelaporan aktivitas menggunakan USE-Questionnaire. Hasil penelitian diketahui bahwa nilai usability sebelum rekomendasi perbaikan adalah $47.58 \%$ dengan predikat cukup dan nilai usability setelah rekomendasi perbaikan adalah $78.27 \%$ dengan predikat baik.

Berdasarkan penelitian terdahulu yang telah dilakukan (Darmawan et al., 2020; Hariyanto et al., 2020; Jubaedah et al., 2020; Lubis et al., 2020; Rizal et al., 2020) menunjukkan bahwa USE-Questionnaire merupakan alat pengukuran usability sistem yang reliabel karena USE-Questionnaire banyak dimanfaatkan di berbagai penelitian dengan konteks pengukuran usability pada objek penelitian yang berbeda-beda.

\section{METODE PENELITIAN}

Jenis penelitian ini adalah penelitian kuantitatif. Tahapan dalam penelitian ini sesuai dengan tahapan yang dilakukan dalam pengujian usability, dimulai dengan memilih metode kuesioner, menetapkan populasi kemudian menentukan jumlah sampel kemudian melakukan proses olah data interpretasi data berdasarkan hasil pengujian(Hadi et al., 2018).

Populasi penelitian adalah seluruh mahasiswa yang berasal dari sepuluh (10) kelas yang sebelumnya telah dibuat di Google Classroom. Pengambilan sampel dilakukan dengan metode purposive sampling dengan jumlah responden sebanyak 150 orang. Data penelitian dikumpulkan menggunakan kuesioner yang dibangun menggunakan Google Form. Link kuesioner penelitian kemudian disebarkan melalui pengumuman di Google Classroom dan grup WhatsApp agar sampel penelitian dapat mengakses dan mengisi kuesioner tersebut. Kuesioner penelitian dapat diakses pada link berikut https://forms.gle/MVvd7xAxLZQ5NxS98.

Sebelumnya, dosen yang bersangkutan membuat kelas yang baru di Google Classroom sebanyak sepuluh (10) kelas sesuai dengan mata kuliah yang dibawakan yang terbagi kedalam tiga mata kuliah dan berasal dari program studi Teknik Informatika dan Program Studi Sistem Informasi STMIK Dipanegara Makassar. Tampilan kelas Google Classroom ditunjukkan pada Gambar 1.

Dosen kemudian memperkenalkan Google Classroom kepada mahasiswa dengan cara membagikan kode kelas kepada mahasiswa agar mahasiswa dapat bergabung kedalam kelas masingmasing.

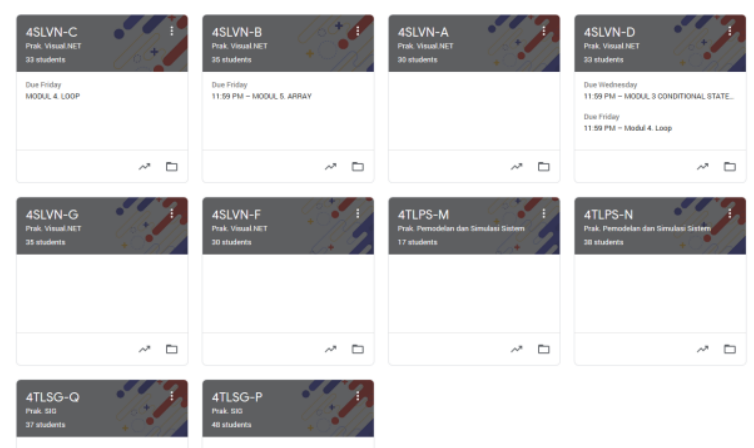

Gambar 1. Daftar Kelas di Google Classroom

Kuesioner penelitian diadaptasi dari model USE-Questionnaire untuk mengukur tingkat usability layanan Google Classroom. Kuesioner telah melalui tahap penyesuaian yaitu kuesioner diterjemahkan ke dalam bahasa Indonesia agar lebih mudah dipahami oleh responden penelitian. Kuesioner terdiri atas tiga puluh (30) indikator pertanyaan yang dibagi menjadi empat variabel yaitu variabel Usefulness (Daya Guna), Ease of Use (Kemudahan Penggunaan), Ease of Learning (Kemudahan Belajar), dan Satisfaction (Kepuasan Pengguna) dengan menggunakan skala likert-4 point dimana poin 1 berarti "sangat tidak setuju" dan 2 untuk "tidak setuju" sedangkan poin 3 untuk "setuju" dan 4 untuk "sangat setuju." Garis besar kuesioner penelitian ditunjukkan pada Tabel 1. Dimensi pengukuran usability dalam USEQuestionnaire diyakini sebagai faktor paling penting untuk mengevaluasi usability (Hariyanto et al., 2020; Machado Faria et al., 2016).

Tabel 1. Kuesioner Penelitian

\begin{tabular}{cll}
\hline VARIABEL & KODE & \multicolumn{1}{c}{ INDIKATOR } \\
\hline $\begin{array}{c}\text { Usefulness } \\
\text { Daya Guna) }\end{array}$ & UL1 & $\begin{array}{l}\text { Google Classroom membantu } \\
\text { saya menjadi lebih efektif. }\end{array}$ \\
\cline { 2 - 3 } & UL2 & $\begin{array}{l}\text { Google Classroom membantu } \\
\text { saya menjadi lebih produktif. }\end{array}$ \\
\cline { 2 - 3 } & UL3 & $\begin{array}{l}\text { Google Classroom memiliki } \\
\text { daya guna }\end{array}$ \\
\cline { 2 - 3 } & UL4 & $\begin{array}{l}\text { Saya dapat mengontrol aktivitas } \\
\text { belajar saya dengan baik sejak } \\
\text { menggunakan Google }\end{array}$ \\
& Classroom \\
\cline { 2 - 3 } & UL5 & $\begin{array}{l}\text { Google Classroom membuat } \\
\text { kegiatan saya lebih mudah } \\
\text { diselesaikan }\end{array}$ \\
\cline { 2 - 3 } & UL6 & $\begin{array}{l}\text { Pemanfaatan Google } \\
\text { Classroom menghemat waktu } \\
\text { saya }\end{array}$ \\
\cline { 2 - 3 } & UL7 & $\begin{array}{l}\text { Pemanfaatan Google } \\
\text { Classroom dapat memenuhi } \\
\text { kebutuhan saya }\end{array}$ \\
& $\begin{array}{l}\text { Pemanfaatan Google } \\
\text { Classroom sesuai dengan } \\
\text { harapan saya }\end{array}$ \\
& Elaogle Classroom mudah \\
& digunakan \\
\hline
\end{tabular}




\begin{tabular}{|c|c|c|}
\hline VARIABEL & KODE & $\begin{array}{l}\text { INDIKATOR } \\
\end{array}$ \\
\hline \multirow{10}{*}{$\begin{array}{l}\text { Ease of Use } \\
\text { (Kemudahan } \\
\text { Penggunaan) }\end{array}$} & EU2 & $\begin{array}{l}\text { Google Classroom adalah } \\
\text { aplikasi yang sederhana }\end{array}$ \\
\hline & EU3 & $\begin{array}{l}\text { Google Classroom mudah } \\
\text { dinavigasikan (user friendly) }\end{array}$ \\
\hline & EU4 & $\begin{array}{l}\text { Tidak terlalu banyak langkah } \\
\text { yang dibutuhkan untuk } \\
\text { menyelesaikan pekerjaan } \\
\text { menggunakan Google } \\
\text { Classroom }\end{array}$ \\
\hline & EU5 & $\begin{array}{l}\text { Tidak terlalu banyak usaha } \\
\text { yang dibutuhkan untuk } \\
\text { menyelesaikan pekerjaan } \\
\text { menggunakan Google } \\
\text { Classroom }\end{array}$ \\
\hline & EU6 & $\begin{array}{l}\text { Google Classroom adalah } \\
\text { aplikasi yang fleksibel }\end{array}$ \\
\hline & EU7 & $\begin{array}{l}\text { Saya dapat menggunakan } \\
\text { Google Classroom tanpa } \\
\text { instruksi tertulis. }\end{array}$ \\
\hline & EU8 & $\begin{array}{l}\text { Saya tidak melihat adanya } \\
\text { ketidakkonsistenan saat saya } \\
\text { menggunakan Google } \\
\text { Classroom. } \\
\end{array}$ \\
\hline & EU9 & $\begin{array}{l}\text { Menurut saya, tiap mahasiswa } \\
\text { menyukai penggunaan Google } \\
\text { Classroom. }\end{array}$ \\
\hline & EU10 & $\begin{array}{l}\text { Jika saya melakukan kesalahan } \\
\text { dalam penggunaan Google } \\
\text { Classroom, saya dapat } \\
\text { memperbaikinya dengan } \\
\text { mudah. }\end{array}$ \\
\hline & EU11 & $\begin{array}{l}\text { Saya berhasil menggunakan } \\
\text { Google Classroom setiap saat. }\end{array}$ \\
\hline \multirow{4}{*}{$\begin{array}{l}\text { Ease of } \\
\text { Learning } \\
\text { (Kemudahan } \\
\text { Belajar) }\end{array}$} & EL1 & $\begin{array}{l}\text { Saya belajar menggunakan } \\
\text { Google Classroom dengan } \\
\text { cepat. }\end{array}$ \\
\hline & EL2 & $\begin{array}{l}\text { Saya dapat dengan mudah } \\
\text { mengingat bagaimana } \\
\text { menggunakan Google } \\
\text { Classroom. }\end{array}$ \\
\hline & EL3 & $\begin{array}{l}\text { Saya cepat terampil } \\
\text { menggunakan Google } \\
\text { Classroom. }\end{array}$ \\
\hline & EL4 & $\begin{array}{l}\text { Google Classroom mudah } \\
\text { dipelajari untuk } \\
\text { menggunakannya. }\end{array}$ \\
\hline \multirow{7}{*}{$\begin{array}{l}\text { Satisfaction } \\
\text { (Kepuasan } \\
\text { Pengguna) }\end{array}$} & ST1 & $\begin{array}{l}\text { Saya puas dengan penggunaan } \\
\text { Google Classroom }\end{array}$ \\
\hline & ST2 & $\begin{array}{l}\text { Saya akan merekomendasikan } \\
\text { Google Classroom kepada } \\
\text { teman saya yang belum pernah } \\
\text { menggunakan }\end{array}$ \\
\hline & ST3 & $\begin{array}{l}\text { Google Classroom sangat } \\
\text { menyenangkan untuk } \\
\text { digunakan. }\end{array}$ \\
\hline & ST4 & $\begin{array}{l}\text { Google Classroom bekerja } \\
\text { sesuai seperti yang saya } \\
\text { inginkan. }\end{array}$ \\
\hline & ST5 & $\begin{array}{l}\text { Google Classroom adalah } \\
\text { aplikasi yang luar biasa. }\end{array}$ \\
\hline & ST6 & $\begin{array}{l}\text { Saya merasa saya perlu untuk } \\
\text { memiliki akun Google } \\
\text { Classroom }\end{array}$ \\
\hline & ST7 & $\begin{array}{l}\text { Google Classroom sangat } \\
\text { nyaman untuk digunakan. }\end{array}$ \\
\hline
\end{tabular}

Instrumen atau alat ukur yang baik harus memiliki validitas dan reliabilitas baik pula. Item pertanyaan mutlak perlu diuji validitas dan reliabilitasnya sebelum analisis statistik dilaksanakan (Natanael, 2013).
Uji validitas dilakukan untuk memastikan seberapa baik suatu instrumen digunakan untuk mengukur konsep yang seharusnya diukur (Jayantika, 2018). Uji reliabilitas adalah uji kekonsistenan instrumen untuk mengukur data (Sarmanu, 2017).

Untuk mengetahui valid atau tidaknya suatu butir instrumen adalah dengan melihat nilai probabilitas koefisien korelasinya (Sinaga et al., 2019). Untuk pengujian reliabilitas dapat mengacu pada nilai Cronbach Alpha $(\alpha)$, di mana suatu konstruk atau variabel dinyatakan reliabel apabila memiliki Cronbach Alpha $(\alpha)>0,7$ (Riyanto and Hatmawan, 2020). Setelah melakukan uji validitas dan reliabilitas, kemudian dilakukan pengukuran usability. Pengujian akan dilakukan dengan perhitungan statistik menggunakan software SPSS 21 dan Microsoft Excel.

\section{HASIL DAN PEMBAHASAN}

\subsection{Karakteristik Responden}

Responden yang dijadikan sebagai sampel di dalam penelitian ini berjumlah sebanyak 150 orang yang diklasifikasikan berdasarkan karakteristik jenis kelamin.

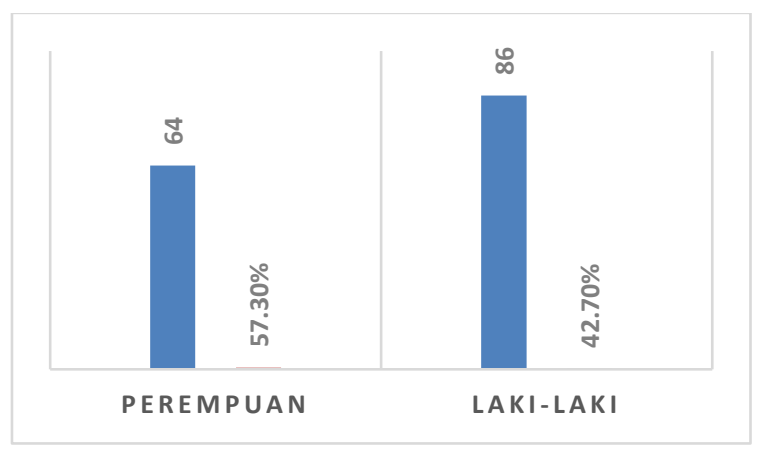

Gambar 2. Distribusi Karakteristik Responden

Berdasarkan data deskriptif yang disajikan pada grafik pada Gambar 2, diketahui bahwa responden yang berjenis kelamin laki-laki adalah sebanyak 86 orang dengan persentase sebesar 57,3\% dan responden yang berjenis kelamin perempuan adalah sebanyak 64 orang dengan persentase sebesar $42,7 \%$ dari jumlah keseluruhan responden sebanyak 150 orang. Berdasarkan data tersebut dapat disimpulkan bahwa responden dalam penelitian ini didominasi oleh responden dengan jenis kelamin laki-laki.

\subsection{Uji Validitas dan Reliabilitas}

Dengan SPSS, uji validitas dan reliabilitas dapat dilakukan dengan sekaligus dengan satu kali cara. Hasil uji validitas disajikan melalui grafik pada Gambar 3 dan Gambar 4. 


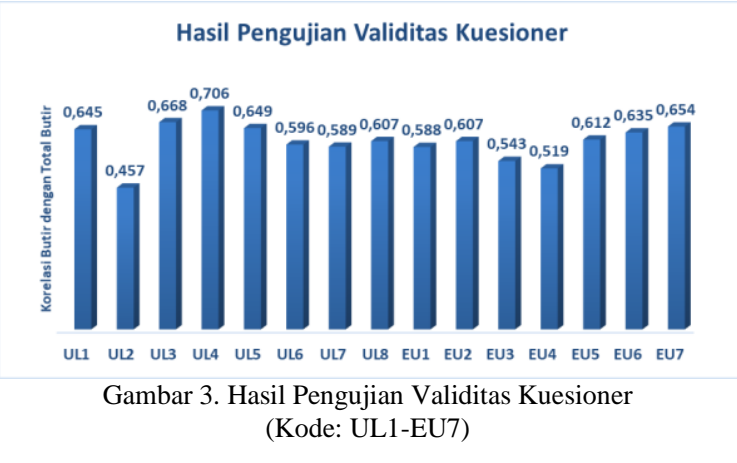

Hasil Pengujian Validitas Kuesioner

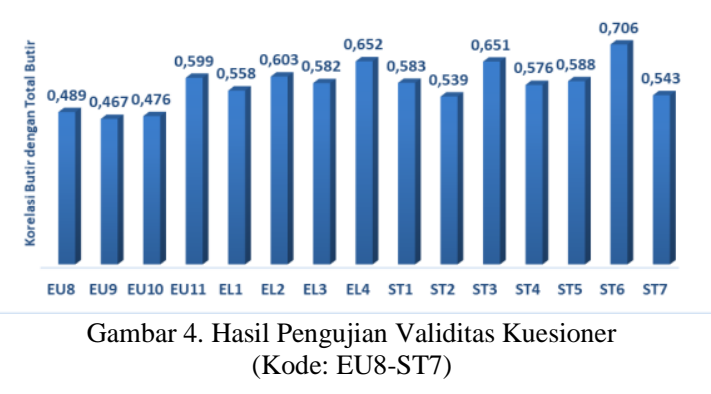

Melalui Gambar 3 dan Gambar 4 dapat diketahui item pertanyaan yang memiliki validitas isi yang baik yaitu memenuhi ketentuan diatas 0,2 (Natanael, 2013). Jika nilai tiap item (Korelasi Butir dengan Total Butir) diatas 0,2; maka item pertanyaan tersebut telah valid. Gambar 3 dan Gambar 4 menerangkan bahwa semua item pertanyaan memiliki nilai korelasi butir dengan total butir diatas 0 ,2. Item pertanyaan kemudian dapat digunakan untuk analisis selanjutnya.

Tabel 2 adalah tabel yang menampilkan nilai reliabilitas berdasarkan nilai Cronbach Alpha $(\alpha)$. Dengan jumlah 30 item pertanyaan $(\mathrm{N})$, nilai Cronbach Alpha $(\alpha)$ yang dihasilkan adalah 0,946. Suatu konstruk atau variabel dinyatakan reliabel apabila memiliki Cronbach Alpha $(\alpha)>0,7$ (Riyanto and Hatmawan, 2020). Berdasarkan pernyataan tersebut, realibilitas keseluruhan butir-butir pertanyaan adalah reliabel.

Tabel 2. Hasil Pengujian Reliabilitas Kuesioner

\begin{tabular}{ccc}
\hline Nilai Cronbach's Alpha & N & \\
\hline .946 & 30 \\
\hline
\end{tabular}

\subsection{Pengukuran Usability}

Tingkat usability Google Classroom diukur menggunakan instrumen penelitian dengan mengadaptasi USE Questionnaire yang dirancang dengan skala likert 4-point dengan nilai skor 1 untuk kriteria jawaban Sangat Tidak Setuju (STS) sampai dengan nilai skor 4 untuk kriteria jawaban Setuju (S).

Untuk menginterpretasikan data dari variabel penelitian, penelitian ini menggunakan analisis deskriptif dengan menggunakan rentang skala. Setelah data kuesioner dikelompokkan dan menghitung skor tiap komponen dengan cara mengalikan seluruh frekuensi data dengan nilai bobotnya, maka langkah selanjutnya adalah menentukan Rentang Skala (RS) dengan rumus (Riyanto and Hatmawan, 2020; Tukino, 2019; Unaradjan, 2019):

$$
R S=\frac{n(m-1)}{m}
$$

dimana:

$n$ = Jumlah sampel

$m=$ Jumlah alternatif jawaban tiap item

Berdasarkan rumus (1) maka Rentang Skala (RS) sebagai dalam penelitian ini adalah sebagai berikut.

$$
\begin{aligned}
R S & =\frac{n(m-1)}{m} \\
R S & =\frac{150(4-1)}{4} \\
R S & =113
\end{aligned}
$$

Setelah Rentang Skala (RS) didapatkan, maka interval Rentang Skala (RS) dalam penelitian ini ditentukan sebagai berikut.

\begin{tabular}{lc}
\multicolumn{2}{c}{ Tabel 3. Rentang Skala (RS) } \\
\hline KRITERIA & RENTANG \\
& SKALA \\
\hline Sangat Buruk/Sangat Tidak setuju & $150-263$ \\
\hline Buruk/Tidak Setuju & $264-375$ \\
\hline Baik/Setuju & $376-488$ \\
\hline Sangat Baik/Sangat Setuju & $489-600$ \\
\hline
\end{tabular}

Dari hasil perhitungan interval tersebut kemudian dapat diketahui respon mahasiswa terhadap seluruh indikator USE-Questionnaire yang digunakan untuk mengukur masing-masing variabel tingkat usability Google Classroom yaitu variabel Usefulness (Daya Guna), Ease of Use (Kemudahan Penggunaan), Ease of Learning (Kemudahan Belajar), dan Satisfaction (Kepuasan Pengguna).

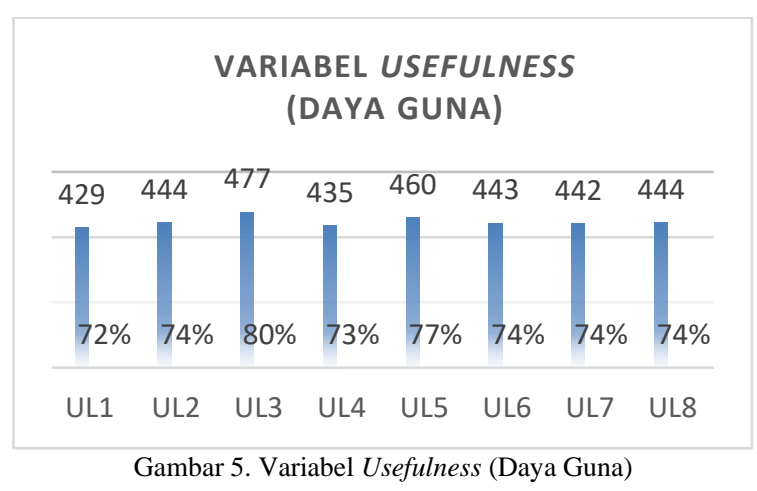

Grafik yang disajikan pada Gambar 5 menyajikan hasil perhitungan tiap indikator pada variabel Usefulness (Daya Guna). Pada grafik terlihat bahwa indikator yang memiliki skor paling tinggi adalah indikator UL3 (Google Classroom memiliki daya guna) dengan skor 477 dan skor terendah adalah indikator UL1 (Google Classroom membantu saya menjadi lebih efektif) dengan skor 429. Berdasarkan tabel Rentang Skala (RS), dengan skor total sebesar 
446,75 maka variabel Usefulness (Daya Guna) termasuk dalam kriteria Baik, dengan kesimpulan bahwa aspek Usefulness (Daya Guna) pada pemanfaatan Google Classroom dirasakan sudah baik oleh mahasiswa.

Berikutnya pada grafik yang disajikan pada Gambar 6, menyajikan hasil perhitungan tiap indikator pada variabel Ease of Use (Kemudahan Penggunaan). Indikator yang memiliki skor paling tinggi adalah indikator EU1 (Google Classroom mudah digunakan) dengan skor 499 dan skor terendah adalah indikator EU9 (Menurut saya, tiap mahasiswa menyukai penggunaan Google Classroom) dengan skor 436. Berdasarkan tabel Rentang Skala (RS), terdapat dua (2) indikator yang termasuk ke dalam kategori Sangat Baik dan sembilan (9) indikator lainnya termasuk kedalam kategori Baik. Secara keseluruhan, variabel Ease of Use (Kemudahan Penggunaan) memiliki skor rata-rata sebesar 463,0 dan termasuk ke dalam kriteria Baik, dengan kesimpulan bahwa aspek Ease of Use (Kemudahan Penggunaan) pada pemanfaatan Google Classroom dirasakan sudah baik oleh mahasiswa.

\section{VARIABEL EASE OF USE \\ (KEMUDAHAN PENGGUNAAN)}

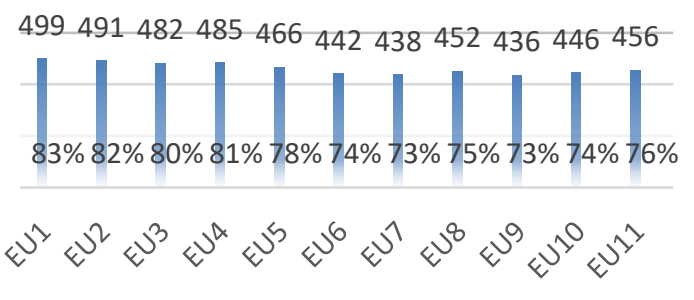

Gambar 6. Variabel Ease of Use (Kemudahan Penggunaan)

Selanjutnya pada grafik yang disajikan pada Gambar 7, menyajikan hasil perhitungan tiap indikator pada variabel Ease of Learning (Kemudahan Belajar). Indikator dengan skor tertinggi yaitu sebesar 483 adalah indikator EL2 (Saya dapat dengan mudah mengingat bagaimana menggunakan Google Classroom) dan indikator EL3 (Saya cepat terampil menggunakan Google Classroom) adalah indikator dengan skor terendah sebesar 459. Secara keseluruhan, variabel Ease of Learning (Kemudahan Belajar) memiliki skor rata-rata sebesar 468,0 dan termasuk ke dalam kriteria Baik berdasarkan tabel Rentang Skala (RS), dengan kesimpulan bahwa aspek Ease of Learning (Kemudahan Belajar) pada pemanfaatan Google Classroom dirasakan sudah baik oleh mahasiswa.

Terakhir adalah Gambar 8 yang menyajikan grafik hasil perhitungan tiap indikator pada variabel Satisfaction (Kepuasan Pengguna). Berdasarkan Gambar 8, indikator ST5 (Google Classroom adalah aplikasi yang luar biasa) memiliki skor tertinggi yaitu sebesar 499 dan indikator ST3 (Google Classroom sangat menyenangkan untuk digunakan) memiliki skor terendah sebesar 424 .

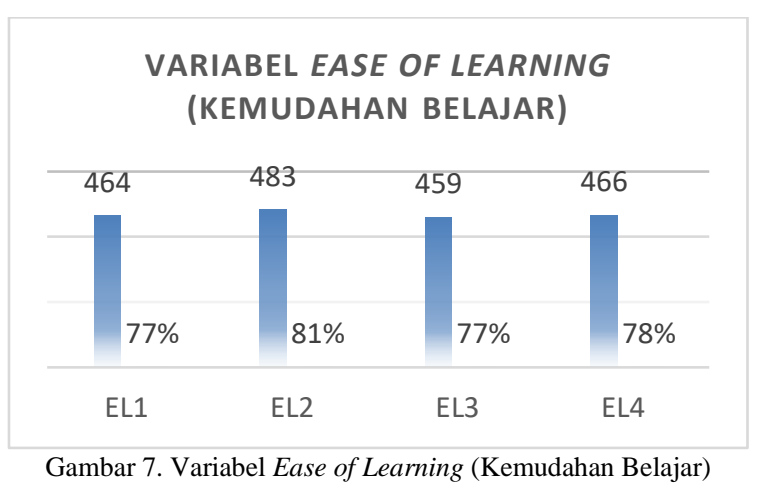

Secara keseluruhan, variabel Satisfaction (Kepuasan Pengguna) memiliki skor rata-rata sebesar 458,71 dan termasuk ke dalam kriteria Baik berdasarkan tabel Rentang Skala (RS), dengan kesimpulan bahwa aspek Satisfaction (Kepuasan Pengguna) pada pemanfaatan Google Classroom dirasakan sudah baik oleh mahasiswa.

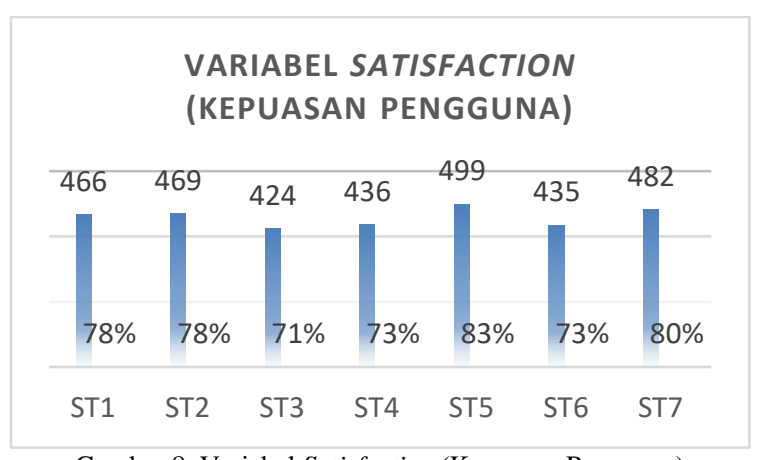

Gambar 8. Variabel Satisfaction (Kepuasan Pengguna)

Selanjutnya pada Tabel 4, disajikan persentase skor seluruh variabel USE-Questionnaire yang digunakan untuk mengukur tingkat usability Google Classroom yaitu variabel Usefulness (Daya Guna), Ease of Use (Kemudahan Penggunaan), Ease of Learning (Kemudahan Belajar), dan Satisfaction (Kepuasan Pengguna).

Tabel 4. Persentase Skor Usability Google Classroom

\begin{tabular}{lcc}
\hline \multicolumn{1}{c}{ Variabel } & Skor & $\begin{array}{c}\text { Persentase } \\
(\boldsymbol{\%})\end{array}$ \\
\hline Usefulnes (Daya Guna) & 446,7 & $74 \%$ \\
\hline $\begin{array}{l}\text { Ease of Use (Kemudahan } \\
\text { Penggunaan) }\end{array}$ & 463,0 & $77 \%$ \\
\hline $\begin{array}{l}\text { Ease of Learning (Kemudahan } \\
\text { Belajar) }\end{array}$ & 468,0 & $78 \%$ \\
\hline Satisfaction (Kepuasan Pengguna) & 458,7 & $76 \%$ \\
\hline \multicolumn{1}{c}{ Skor Keseluruhan } & $\mathbf{4 5 9 , 1}$ & $\mathbf{7 6 \%}$ \\
\hline
\end{tabular}

Berdasarkan data yang disajikan pada Tabel 4, dapat disimpulkan bahwa sebanyak $74 \%$ responden setuju bahwa aspek Usefulnes (Daya Guna) dirasakan sudah baik oleh mahasiswa, $77 \%$ responden setuju bahwa aspek Ease of Use (Kemudahan Penggunaan) dirasakan sudah baik oleh mahasiswa, 78\% responden setuju bahwa aspek Ease of Learning (Kemudahan Belajar) dirasakan sudah baik oleh mahasiswa, dan $76 \%$ responden setuju bahwa aspek Satisfaction (Kepuasan Pengguna) dirasakan sudah 
baik oleh mahasiswa. Secara keseluruhan, sebanyak 76\% mahasiswa setuju tingkat usability Google Classroom dirasakan sudah baik dan penggunaan layanan Google Classroom telah efektif, efisien, dan memberikan kepuasan terhadap mahasiswa.

\section{KESIMPULAN}

Berdasarkan hasil pengukuran usability terhadap penggunaan layanan Google Classroom diperoleh nilai rata-rata untuk keseluruhan variabel Usefulness (Daya Guna), Ease of Use (Kemudahan Penggunaan), Ease of Learning (Kemudahan Belajar), dan Satisfaction (Kepuasan Pengguna) adalah 459,1 atau sebesar 76\%. Jika disesuaikan dengan tabel Rentang Skala (RS) maka dapat disimpulkan bahwa mahasiswa setuju tingkat usability Google Classroom dirasakan sudah baik dan penggunaan layanan Google Classroom telah efektif, efisien, dan memberikan kepuasan terhadap mahasiswa dengan tingkat presentase sebesar $76 \%$.

Penelitian ini merupakan penelitian awal yang masih belum sempurna sehingga membutuhkan penelitian lanjutan untuk melengkapi dan memperdalam informasi serta hasil temuan penelitian. Saran untuk penelitian selanjutnya, dilakukan analisis komparasi beberapa model yang dapat digunakan untuk pengujian usability sistem informasi.

\section{DAFTAR PUSTAKA}

ABIDAH, A., HIDAAYATULLAAH, H.N., SIMAMORA, R.M., FEHABUTAR, D., MUTAKINATI, L., 2020. The Impact of Covid-19 to Indonesian Education and Its Relation to the Philosophy of "Merdeka Belajar." Studies in Philosophy of Science and Education 1, 38-49.

ALQAHTANI, A., 2019. Usability testing of Google cloud applications: students' perspective. Journal of Technology and Science Education $\quad 9$, 326-339. https://doi.org/10.3926/jotse.585

BEVAN, N., EARTHY, J., 2017. Benefiting from ISO Standards, in: Norman, K.L., Kirakowski, J. (Eds.), The Wiley Handbook of Human Computer Interaction. John Wiley \& Sons, Ltd, Chichester, UK, pp. 51-69. https://doi.org/10.1002/9781118976005.ch3

BLANCHARD, A., PRIOR, F., GILBERT, L., DAWSON, T., 2018. Technology Implementation Case Studies: Lincus Software as a Service, in: Dastbaz, M., Arabnia, H., Akhgar, B. (Eds.), Technology for Smart Futures. Springer International Publishing, Cham, pp. 141-167. https://doi.org/10.1007/978-3-319-601373_7

DARMAWAN, W., SUNARDI, S., YUDHANA, A., 2020. Analysis of Mobile Based Activity
Reporting Systems Using Usability Testing Methods and Use Questioners. Jurnal Mantik 4, 69-73.

DIEMERT, S., WEBER, J., PRICE, M., 2017. Considering the Language of Computerized Order Entry Systems. Stud Health Technol Inform 234, 87-92.

GAO, M., KORTUM, P., OSWALD, F., 2018. Psychometric Evaluation of the USE (Usefulness, Satisfaction, and Ease of use) Questionnaire for Reliability and Validity. Proceedings of the Human Factors and Ergonomics Society Annual Meeting 62, 1414-1418. https://doi.org/10.1177/1541931218621322

HADI, K.R., AZ-ZAHRA, H.M., FANANI, L., 2018. Analisis Dan Perbaikan Usability Aplikasi Mobile KAI Access Dengan Metode Usability Testing Dan Use Questionnaire. Jurnal Pengembangan Teknologi Informasi dan Ilmu Komputer 2, 2742-2750.

HARIYANTO, D., TRIYONO, MOCH.B., KÖHLER, T., 2020. Usability evaluation of personalized adaptive e-learning system using USE questionnaire. Knowledge Management \& E-Learning: An International Journal 85-105. https://doi.org/10.34105/j.kmel.2020.12.00 5

HENUKH, A., ROSDIANTO, H., OIKAWA, S., 2020. Implementation of Google Classroom as Multimedia Learning. JIPF (Jurnal Ilmu Pendidikan Fisika) 5, 38. https://doi.org/10.26737/jipf.v5i1.1539

JAMIL, G.L., RIBEIRO, F., MALHEIRO DA SILVA, A., MARAVILHAS LOPES, S. (EDS.), 2020. Handbook of Research on Emerging Technologies for Effective Project Management:, Advances in Logistics, Operations, and Management Science. IGI Global. https://doi.org/10.4018/978-1-5225-9993-7

JAYANTIKA, I.P.A.A.P. DAN I.G.A.N.T., 2018. Panduan Penelitian Eksperimen Beserta Analisis Statistik dengan SPSS. Deepublish.

JUBAEDAH, Y., YULIA, C., MUKTIARNI, M., MAOSUL, A., 2020. Usability testing electronic rubric of performance assessment. Journal of Physics: Conference Series 1456, 012016. https://doi.org/10.1088/17426596/1456/1/012016

KAEWSAIHA, P., 2019. Usability of the Learning Management System and Choices of Alternative.

LUBIS, B.O., SALIM, A., JEFI, J., 2020. Evaluasi Usability Sistem Aplikasi Mobile JKN Menggunakan Use Questionnaire. Jurnal SAINTEKOM 10, 65-76. https://doi.org/10.33020/saintekom.v10i1.1 31 
MACHADO FARIA, T.V., PAVANELLI, M., BERNARDES, J.L., 2016. Evaluating the Usability Using USE Questionnaire: Mindboard System Use Case, in: Zaphiris, P., Ioannou, A. (Eds.), Learning and Collaboration Technologies, Lecture Notes in Computer Science. Springer International Publishing, Cham, pp. 518-527. https://doi.org/10.1007/978-3-319-394831_47

NATANAEL, S., YONATHAN, 2013. Mahir Menggunakan SPSS secara Otodidak. Elex Media Komputindo.

PRASTYO, D., UDIN, S., BAKHTIAR, M.Y., 2019. Development of the Human Resources Information System (HRIS) Based on Usability Analysis with Usefulness, Satisfaction, Ease to Use (USE) Questionaire and Cognitive Walkthrough Methods. bit-Tech 1, 150-162. https://doi.org/10.32877/bt.v1i3.77

RANGRAZ JEDDI, F., NABOVATI, E., BIGHAM, R., KHAJOUEI, R., 2020. Usability evaluation of a comprehensive national health information system: relationship of quality components to users' characteristics. International Journal of Medical Informatics 133, 104026. https://doi.org/10.1016/j.ijmedinf.2019.104 026

RIYANTO, S., HATMAWAN, A.A., 2020. Metode Riset Penelitian Kuantitatif Penelitian Di Bidang Manajemen, Teknik, Pendidikan Dan Eksperimen. Deepublish.

RIZAL, M.F., WIDODO, A.P., ADI, K., RIYANTO, D.E.R., NURHAYATI, O.D., 2020. Usability testing mozita application based on use questionnaire model. Journal of Physics: Conference Series 1524, 012104. https://doi.org/10.1088/17426596/1524/1/012104

SARMANU, 2017. Dasar Metodologi Penelitian Kuantitatif Kualitatif dan Statistika. Airlangga University Press.

SEPTIYANA, L., WIDIYANINGSIH, W., 2020. Supporting 21st century English teaching and learning through Google Classroom at university level. AKSARA: Jurnal Bahasa dan Sastra 21.

SINAGA, E.K., MATONDANG, Z., SITOMPUL, H., 2019. STATISTIKA: Teori dan Aplikasi Pendidikan. Yayasan Kita Menulis.

TUKINO, T., 2019. Analisis Kualitas Layanan Website SIKMB menggunakan Metode Webqual 4.0 (Studi pada Badan Pengusahaan (BP) Batam). KLIK Kumpulan Jurnal Ilmu Komputer 6, 1-15. https://doi.org/10.20527/klik.v6i1.149
UNARADJAN, D.D., 2019. Metode Penelitian Kuantitatif. Penerbit Unika Atma Jaya Jakarta.

UNESCO, 2020. COVID-19 Educational Disruption and Response [WWW Document]. Unesco. URL

https://en.unesco.org/covid19/educationres ponse (accessed 5.15.20).

VERAWARDINA, U., ASNUR, L., LUBIS, A.L., HENDRIYANI, Y., RAMADHANI, D., DEWI, I.P., DARNI, R., BETRI, T.J., SUSANTI, W., SRIWAHYUNI, T., 2020. Reviewing Online Learning Facing the Covid-19 Outbreak. Journal of Talent Development and Excellence 12, 385-392. 